\title{
STUDIES ON THE RESPIRATORY AND SYSTEMIC CELL-MEDIATED IMMUNITY
}

\section{DEVELOPMENT OF LOCAL AND SYSTEMIC CELL-MEDIATED IMMUNITY IN GUINEA PIGS GIVEN KILLED BCG INTRATRACHEALLY OR PARENTERALLY}

\author{
YOSHIHARU AIZAWA
}

\author{
Department of Internal Medicine, School of Medicine, \\ Keio University, Tokyo, Japan
}

(Received for publication January 31,1975 )

\begin{abstract}
Local cell-mediated immunity (CMI) in the respiratory tract and systemic CMI were evaluated. Cellular immune response was tested by the estimation of delayed skin reactivity to purified protein derivative of $M$. tuberculosis (PPD) and inhibition of macrophage migration (IMM) at various intervals after the immunization of guinea pigs with heat killed bacillus Calmette Guérin (BCG). As an indicator of local respiratory sensitivity, IMM using bronchial washing cells was adopted, while as an indicator of systemic immune response, IMM with peritoneal exudate cells and skin reactivity to PPD were used.

The animals immunized with heat killed BCG via intratracheal route developed significantly greater local CMI than animals immunized via subcutaneous route, whereas parenterally immunized animals showed greater systemic immunity than intratracheally immunized animals. From the results of delayed skin reaction and IMM with pulmonary or peritoneal cells, skin reactions correlated with IMM by peritoneal exudate cells but not with IMM by respiratory tract cells.

CMI was also evaluated by resistance to infection of $M$. tuberculosis H37Rv challenged via intratracheal or subcutaneous route. Intratracheal immunization induced higher protection against intratracheal challenge than subcutaneous immunization. On the contrary, subcutaneous immunization developed higher resistance to subcutaneous infection. Therefore, local and systemic protection against infection correlated with either local and systemic CMI measured by IMM respectively.
\end{abstract}

\section{INTRODUCTION}

While secretory antibodies have been shown to be important in the defense mechanism in respiratory infections,,$^{1,2,3}$ relatively little information is available 
concerning local CMI in the lung. With the development of an in vitro test which may correlate with cellular immunity, $, 4,6,6$ the local immune response in the lung can be measured with cells obtained by washing the lower respiratory tract. Galindo and $\mathrm{Myrvik}^{7,8}$ described the inhibition of migration of alveolar cells in the presence of PPD using rabbits immunized intravenously with BCG. Concurrently, Henney and Waldman, ${ }^{9}$ using dinitrophenylated human $\gamma$-globulin as antigen, immunized guinea pigs with nose drops, after which bronchial washing cells mixed with normal peritoneal macrophages showed the migration inhibition in the presence of antigen, whereas systemic cellular response was not observed. Later other results demonstrating dissociation between local and systemic CMI with various antigens have been published. ${ }^{10-18}$

The purpose of this work was to compare the local and systemic cellular immune response to mycobacterium in animals immunized by different routes using delayed skin test, macrophage migration test and resistance to infection.

\section{MATERIALS AND METHODS}

ANIMALS. Female Hartley guinea pigs weighing approximately $400 \mathrm{~g}$ were used.

IMMUNIZATION. Guinea pigs were immunized with a single injection of $1 \mathrm{mg}$ (high dose) or $0.1 \mathrm{mg}$ (low dose) of commercially available BCG (Japan BCG Laboratory), killed by heating in boiling water bath for $15 \mathrm{~min}$. and suspended in $0.1 \mathrm{ml}$ of saline. The antigen was injected subcutaneously into the thigh or into the surgically exposed trachea under light anesthesia with sodium thiopental.

SKIN TEST. The tuberculin skin test was conducted by intracutaneous injection with $1 \mathrm{mcg}$ of PPD (Japan BCG Laboratory) in $0.1 \mathrm{ml}$ of phosphate buffer solution in the depilated flank at various intervals after immunization. The diameter of erythema was measured 24 hours after injection.

PREPARATION OF CELL SUSPENSIONS. At various intervals after immunization, seven animals of each group were bled to death. Bronchial washing cells were obtained by washing the bronchi with $10 \mathrm{ml}$ of sterile Hanks' balanced salt solution (HBSS). Oil-treated peritoneal exudate cells from immunized or nonimmunized animals were harvested by washing the peritoneal cavity with $20 \mathrm{ml}$ of heparinized HBSS. Pulmonary exudate cell suspension contained approximately $15-20 \%$ of lymphocytes and peritoneal exudate cells contained $3-5 \%$ of lymphocytes.

MACROPHAGE MIGRATION INHIBITION TEST. This test was carried out using a slightly modified technique of David et al.5,19 Briefly, the pulmonary 
cells from sensitized animals were diluted $1: 3$ with normal peritoneal cells, whereas sensitized peritoneal cells were used unmixed. The final concentration was adjusted $8 \times 10^{7}$ cells $/ \mathrm{ml}$ with HBSS containing $0.5 \%$ lactalbumin hydrolysate, $20 \%$ fetal calf serum, $100 \mathrm{meg} / \mathrm{ml}$ streptomycin and $100 \mathrm{units} / \mathrm{ml}$ penicillin. Capillary tubes, which were previously sealed at one end by heating, were filled with cell suspension by vacuumizing the container. Capillary tubes were centrifuged at $150 \mathrm{G}$ for $3 \mathrm{~min}$. Each capillary was cut at the cell-medium interface and incubated in a tissue chamber containing the medium with or without $\mathbf{1 5}$ $\mathrm{mcg} / \mathrm{ml}$ of PPD. The size of the migrating area was measured by a microscope equipped with an ocular micrometer after incubation for 24 hours at $37^{\circ} \mathrm{C}$. The average area was calculated with multiplication of diameters of two directions. The per cent IMM was then calculated according to the following formula:

$$
\% \text { Inhibition }=100-\frac{\text { Average area of migration with antigen }}{\text { Average area of migration without antigen }} \times 100
$$

PROTECTION TEST. Four animals of each group immunized by intratracheal or subcutaneous route with $1 \mathrm{mg}$ of heat killed BCG four weeks previously, were challenged by intratracheal or subcutaneous route with $0.001 \mathrm{mg}$ of $\mathrm{M}$. tuberculosis $\mathrm{H} 37 \mathrm{Rv}$ in $0.1 \mathrm{ml}$ of Dubos albumin liquid medium (60 viable units). Before use, these organisms had been cultured in Dubos albumin liquid medium for one week and adjusted with photoelectric photometer. Animals were sacrificed three weeks after challenge. The number of living mycobacteria was counted four weeks after inoculation with $0.1 \mathrm{ml}$ of homogenates of the lung, liver and spleen from each animal on $1 \%$ Ogawa's medium.

\section{RESULTS}

MIGRATION INHIBITION TEST. The results of IMM obtained with respiratory tract cells and peritoneal exudate cells are illustrated in Fig. 1 and Table 1. The measurable response in either cell population was observed from 2 weeks with a peak at 6 or 8 weeks after immunization. The animals immunized by intratracheal route with a higher dose of BCG exhibited greater IMM by bronchial washing cells than IMM by peritoneal cells at 2 and 4 weeks after inoculation $(\mathrm{p}<0.05)$. They also developed a higher degree of IMM by pulmonary cells than the lower dose given animals $(p<0.01)$. In the animals immunized intratracheally with a lower dose, significant difference between IMM by bronchial washing cells and peritoneal cells could not be detected.

In the animals inoculated both with higher and lower dose by subcutaneous injection, peritoneal cells demonstrated more active response than respiratory 

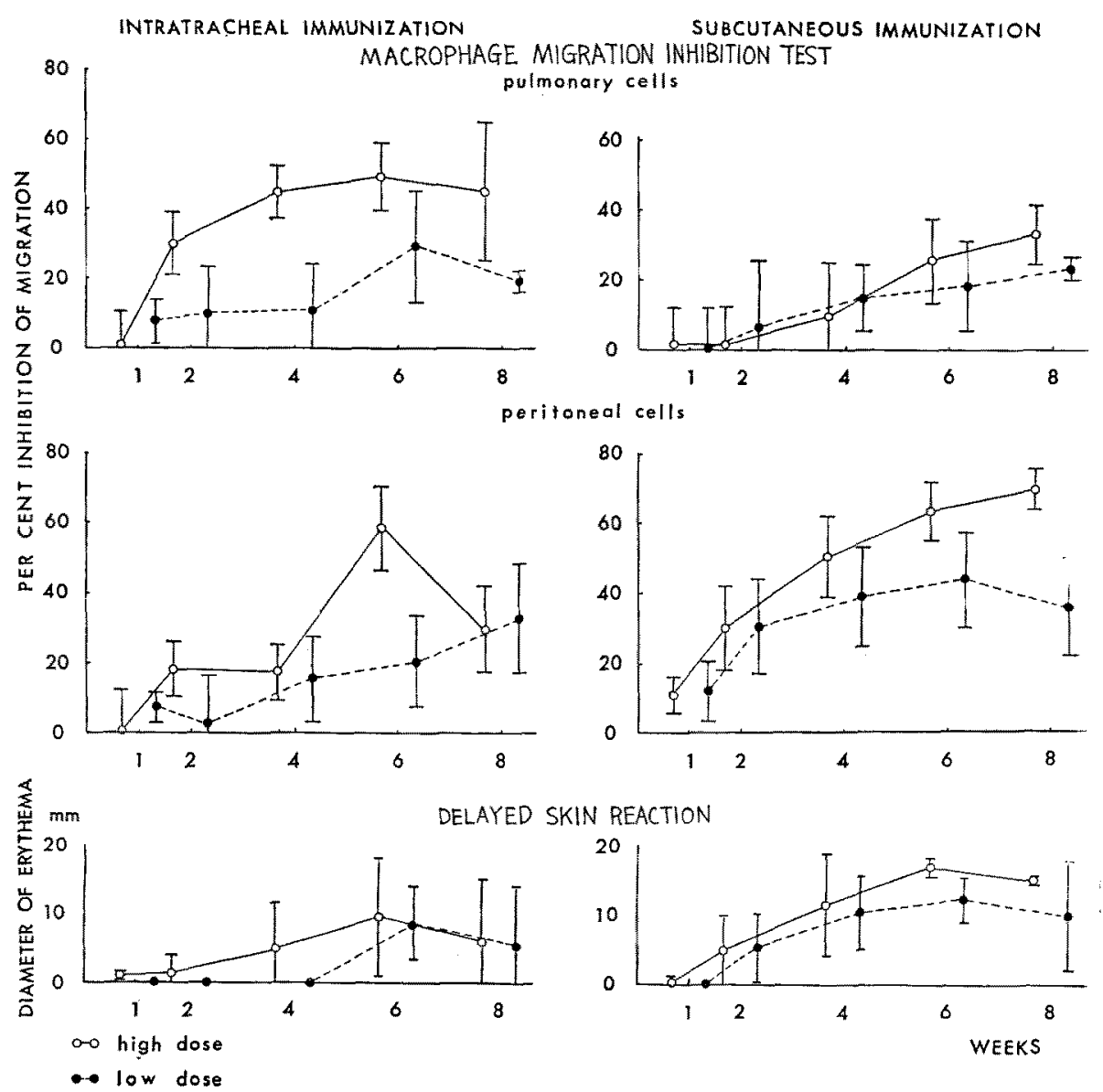

Fig. 1 Development of inhibition of macrophage migration by pulmonary cells or peritoneal cells and delayed skin reaction to PPD. Each dot and bar represents. respectively mean value and standard deviation of 5 to 7 determinations.

tract cells at each week $(p<0.05)$. Subeutaneous immunization with a higher dose showed greater IMM by peritoneal cells than with a lower dose at 6 and 8 . weeks $(\mathrm{P}<0.05)$.

In the higher dose group, bronchial washing cells from intratracheally immunized animals exhibited greater IMM than those of parenterally sensitized animals at 2,4 and 6 weeks after inoculation $(\mathrm{p}<0.01)$. Immunization with a lower dose, however, presented no remarkable difference of IMM between two groups. On the contrary, subcutaneous administration of a higher dose was more effective in inducing peritoneal cells to inhibit macrophage migration than intra- 
Table 1

Inhibition of macrophage migration by pulmonary and peritoneal cells

\begin{tabular}{|c|c|c|c|c|}
\hline \multirow{2}{*}{$\begin{array}{c}\text { Route of } \\
\text { Immunization }\end{array}$} & \multirow{2}{*}{$\begin{array}{c}\text { Source of } \\
\text { Lymphocytes }\end{array}$} & \multicolumn{3}{|c|}{ Inhibition of Macrophage Migration } \\
\hline & & $\begin{array}{l}2 \text { and } 4 \\
\text { Weeks* }\end{array}$ & $\begin{array}{l}6 \text { and } 8 \\
\text { Weeks }\end{array}$ & $\begin{array}{l}2 \text { to } 8 \\
\text { Weeks }\end{array}$ \\
\hline \multirow{2}{*}{ Intratracheal } & Pulmonary & $37.6 \pm 10.9^{* *}$ & $47.3 \pm 15.1$ & $42.5 \pm 14.0$ \\
\hline & Peritoneal & $17.8 \pm 7.4$ & $44.2 \pm 18.9$ & $31.0 \pm 19.4$ \\
\hline \multirow{2}{*}{ Subcutaneous } & Pulmonary & $5.5 \pm 13.4$ & $29.2 \pm 10.3$ & $17,4 \pm 17.2$ \\
\hline & Peritoneal & $40.4 \pm 15.4$ & $66.7 \pm 7.6$ & $53.5 \pm 17.6$ \\
\hline
\end{tabular}

* Following immunization with $1 \mathrm{mg}$ of heat killed BCG.

* Mean per cent inhibition of 14 determinations \pm standard deviation.

tracheal injection at 2,4 and 8 weeks $(p<0.01)$. In the lower dose group, subcutaneous immunization was more effective at 2,4 and 6 weeks after inoculation $(\mathrm{p}<0.01)$.

TUBERCULIN TEST. One week after immunization with BCG via any routes and with any doses, tuberculin skin tests were negative. At 4 and 8 weeks postimmunization with a higher dose, the mean diameter of erythema after 24 hours in subcutaneously immunized animals was significantly greater than that in intratracheally immunized animals $(p<0.05)$. In the lower dose group, subcutaneous immunization was more effective in eliciting delayed skin reaction than intratracheal inoculation at 2 and 4 weeks $(p<0.05)$.

RELATIONSHIP BETWEEN IMM AND TUBERCULIN SKIN TEST. The chronological course of IMM by peritoneal and alveolar cells was correlated with that of skin test after immunization (Fig. 1). However, by comparison of diameter of erythema and IMM in each animal, a correlation was detected with peritoneal cells but not respiratory tract cells (Fig. 2, 3).

PROTECTION. The results presented in Table 2, demonstrated that intratracheal immunization induced higher protection against intratracheal challenge with M. tuberculosis $\mathrm{H} 37 \mathrm{v}$ than did subcutaneous immunization. On the contrary, against subcutaneous challenge, subcutaneously immunized animals developed higher resistance than intratracheally immunized animals.

HISTOLOGY. The lungs from two of the three animals which had been immunized intratracheally with $1 \mathrm{mg}$ of heat killed BCG two weeks previously showed severe nonsuppurative bronchopneumonia without discrete granulomatous lesion (Fig. 4), another showed only scattered infiltration of mononuclear cells. Four weeks after intratracheal immunization, similar to above described findings were found in both animals, one of which showed severe nonsuppurative bronchop- 


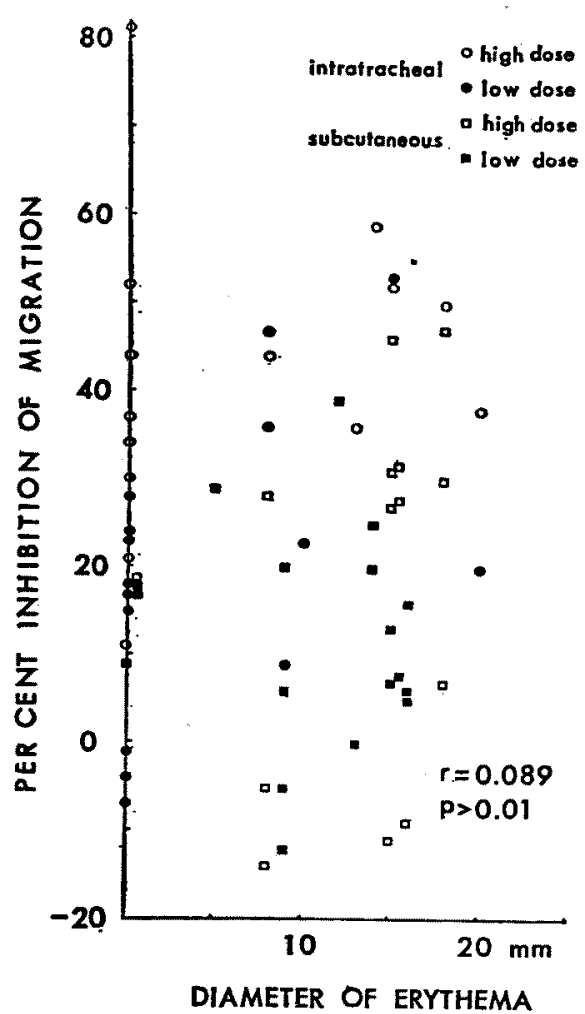

Fig. 2 Correlation between inhibition of macrophage migration by pulmony cells and delayed skin reaction at 2 to 8 weeks.

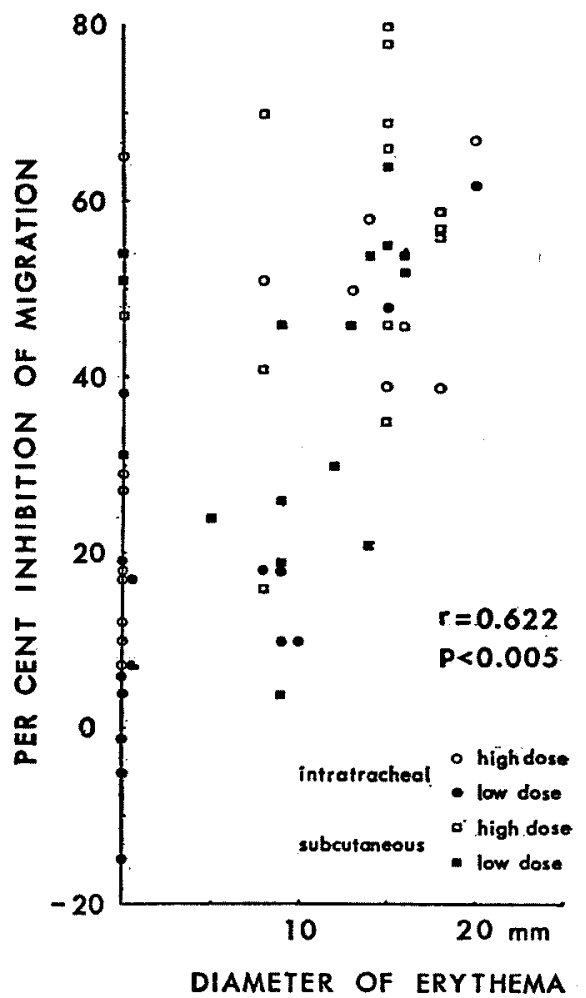

Fig. 3 Correlation between inhibition of macrophage migration by peritoneal cells and delayed skin reaction at 2 to 8 weeks.

Table 2

Immunizing effect of heat killed $B C G$ by various routes

\begin{tabular}{c|c|c|r|r}
\hline \multirow{2}{*}{ Route of Challenge } & $\begin{array}{c}\text { Route of } \\
\text { Immunization }\end{array}$ & Lung & Liver & Spleen \\
\cline { 2 - 5 } & Intratracheal & 183 & 35 & 673 \\
& Subcutaneous & 1075 & 0 & 1769 \\
& No & 4386 & 1465 & 989 \\
& Intratracheal & 0 & 169 & 1269 \\
& Subcutaneous & 0 & 0 & 0 \\
& No & 0 & 593 & 2853 \\
\hline
\end{tabular}

* Average of four determinations. 


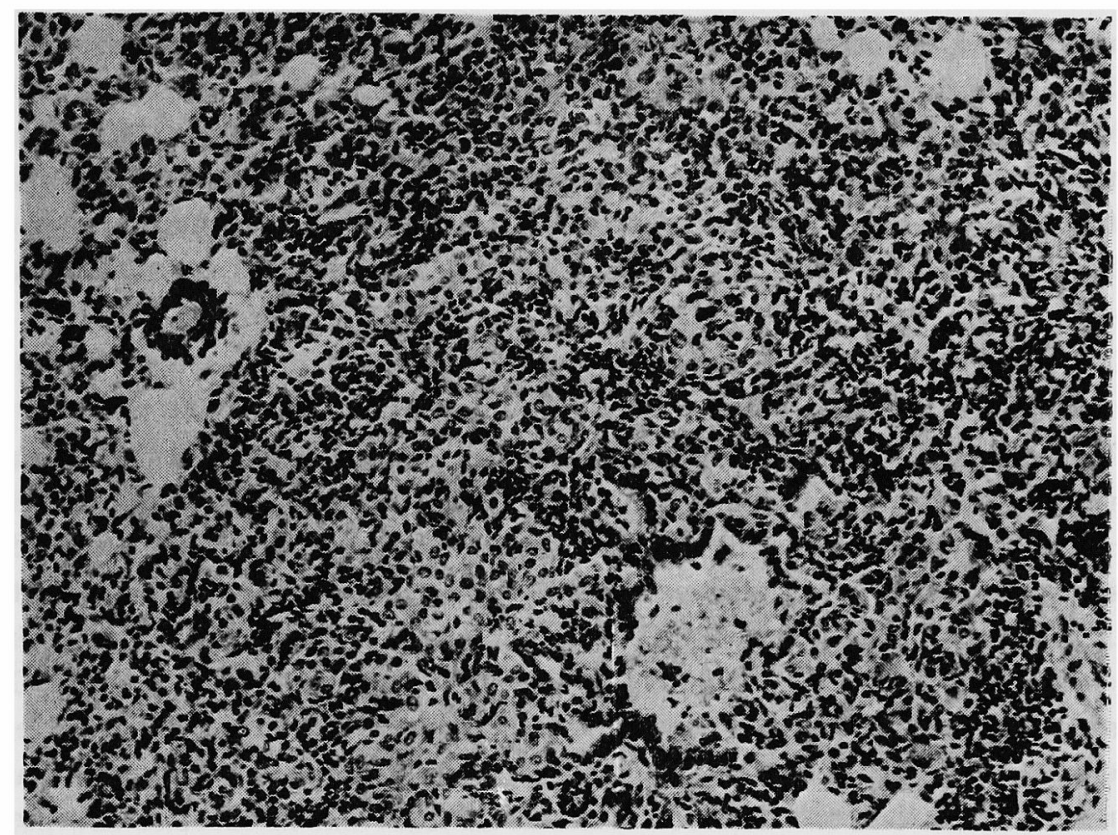

Fig. 4 Hitology of the lung from the guinea pig immunized intratracheally with $1 \mathrm{mg}$ of heat killed BCG two weeks previously. There is a severe nonsuppurative bronchopneumoaia. Hematoxylin and eosin; $\times 200$.

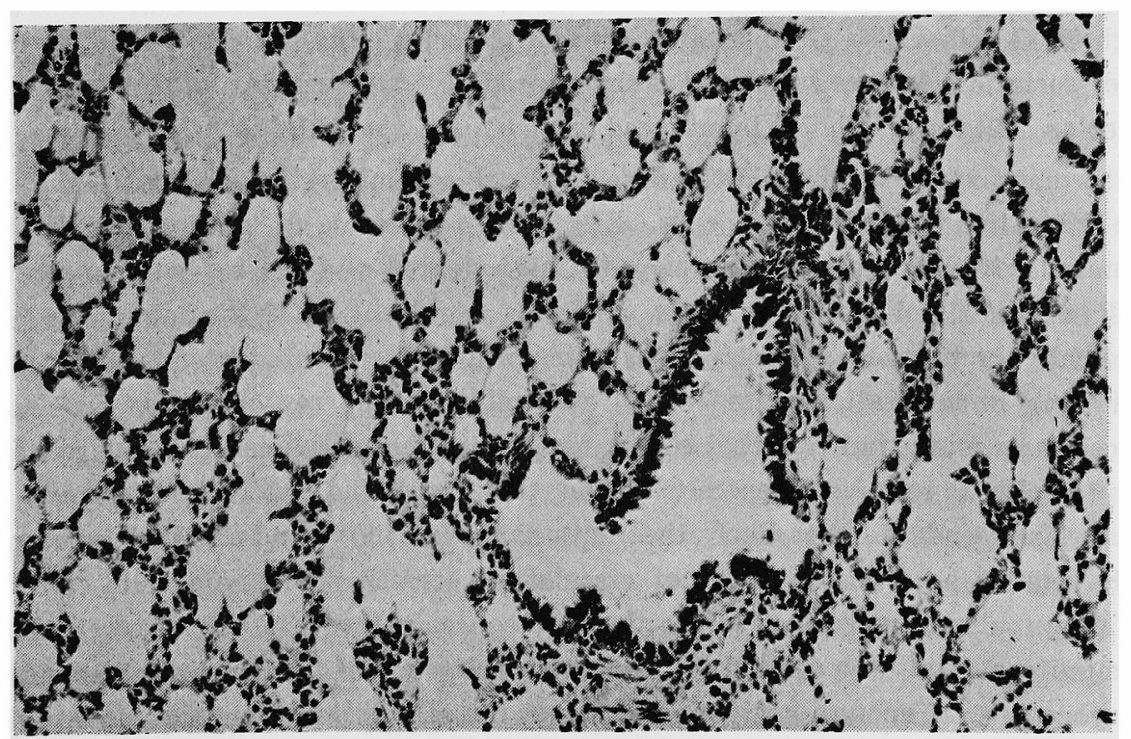

Fig. 5 Histology of the lung from the guinea pig immunized subcutaneously with $1 \mathrm{mg}$ of heat killed BCG two weeks previously. There is a slight interstitial infiltration of mononuclear cells. Hematoxylin and ensin; $\times 200$. 
neumonia and the other exhibited mild lesion. Five animals immunized via subcutaneous route with $1 \mathrm{mg}$ of killed BCG two and four weeks previously developed mild nonsuppurative bronchopneumonia or slight interstitial infiltration of mononuclear cells (Fig. 5). Accordingly, there was no difference in quality of histological lesions of the lungs between intratracheal and subcutaneous immunization, whereas difference in quantity between them was demonstrated.

\section{DISCUSSION}

Intratracheal immunization with a higher dose of killed BCG was more effective in inducing pulmonary cells to inhibit macrophage migration than peritoneal cells. On the contrary, subcutaneous immunization with either dose was more effective in eliciting peritoneal cells to inhibit macrophage migration than pulmonary cells. Therefore, CMI in the lung was more effectively obtained by local inoculation than by parenteral administration, whereas systemic CMI was acquired more effectively by parenteral route. As already described elsewhere,5,20 IMM with peritoneal exudate cells correlated significantly with delayed skin reaction in the present study. But IMM by bronchial washing cells revealed no correlation with intensity of skin test. Yamamoto et $\mathrm{al}^{21}$ also demonstrated that footpad sensitivity correlated with IMM by peritoneal cells, but did not correlate with IMM employing lung cells in mice immunized via various routes with BCG cell walls. Galindo and Myrvik $^{8}$ described the results which revealed a dissociation between delayed skin sensitivity and migration inhibition of alveolar cells from rabbits immunized intravenously with BCG.

Immunization with a lower dose by local administration scarcely inhibited the migration of pulmonary cells. Also, some, but not all, animals locally immunized with a higher dose developed a high degree of IMM by both pulmonary and peritoneal cells. Furthermore, a higher degree of IMM by pulmonary cells in locally immunized animals was significantly demonstrated at 2 and 4 weeks following immunization, after which systemic immune response also developed. These facts might indicate that compartmentalization of cellular immune response is partially a relative phenomenon and that local and systemic CMI are not totally independent. It is likely that both skin sensitivity and IMM by peritoneal cells require a critical number of circulating sensitive lymphoid cells, whereas IMM by pulmonary cells requires their presence in the respiratory tract. Local immunity may also be related to the localized amount of antigen which sensitizes lymphocytes. If enough antigen enters into the circulation from the local region, systemic CMI may also develop. This hypothesis was sustained by the pulmonary histological findings, in which intratracheal immunization elicited more severe 
nonsuppurative bronchopneumonia than subcutaneous immunization. But it remains to be discussed where these lymphocytes come from. Histological examination of the lung of guinea pigs showed as numerous lymphoid tissue around peripheral respiratory tracts as shown in other animals.22 These lymphoid tissue: of rabbits appeared to lack immunoglobulin containing cells. ${ }^{22}$ Therefore, sensitized lymphocytes in these tissues may be related to local CMI of the lung.

In the study of Spencer et al, ${ }^{23}$ intensity of IMM was greatest at one week following nasal and footpad immunization with $0.2 \mathrm{mg}$ of killed $\mathrm{H} 37 \mathrm{Rv}$, and then decreased in the course of time. In the present study, however, IMM was not. detected at one week and it developed from 2 weeks until 6 or 8 weeks after imminization. This discord may be due to the quality and dose of antigen or preparation of cell suspension employed in estimating IMM.

Previous reports demonstrated that cells obtained from animals immunized. intravenously exhibited inhibition of migration in the absence of antigen. 8,10 This phenomenon, called autoinhibition, was interpreted by the stimulation of sensitized lymphocytes by antigen released from granulomatous alveolar macrophages in bronchial washing cells. Neither autoinhibition nor granulomatous lesion was observed in this study as in other reports. ${ }^{9,11}$ It may be related to the kind of animals, dosage of antigen, method of preparing antigen, presence or absence of granulomatous lesion, or the composition of cell population used in the migration inhibition test.

When CMI strictly means resistance to infection, it has been suggested for many years that delayed type hypersensitivity (DTH) and CMI were causally related. ${ }^{24}$ However, frequent inability to detect DTH in animals demonstrating overt antituberculous immunity was evidenced. ${ }^{25,26,27}$ This fact threw doubt on the true nature of this relationship. In the study of Yamamoto et al, ${ }^{21}$ local activity of IMM, regarded as an expression of DTH, correlated with protection against airborne infection with $M$. tuberculosis. In the present study, as either local or systemic inoculation developed greater IMM of pulmonary or peritoneal cells respectively, local immunization appeared more effective in resistance to intratracheal challenge than subcutaneous inoculation. On the other hand, parenteral immunization induced higher resistance to subcutaneous infection. Therefore, this study also suggested the presence of a correlation between sensitivity to $\mathrm{PPD}$ and antituberculous resistance. The result that parenterally immunized animals demonstrated an uncontrollable number of viable units of $M$. tuberculosis. H37Rv in the spleen after intratracheal challenge was probably due to weak and unstable immunogenecity of killed mycobacteria as commonly admitted. ${ }^{28,29,30}$

Accordingly, the above described findings suggest that local CMI of respiratory tract can exist independently at an early time after intratracheal immuniza- 
tion. Therefore, a lack of demonstrable delayed skin reaction or systemic CMI should not be regarded as valid evidence for the absence of cellular immunity of the lung. Local administration of antigen can elicit local cellular immunity more effectively and quickly than parenteral immunization and this can occur vice versa.

\section{ACKNOWLEDGEMENT}

The author wishes to express his gratitude to Dr. J. Gomi, Prof. F. Gotoh, T. Aoyagi, T. Kawai and Y. Yamada for their valuable criticisms and to K. Kaneko and A. Fukushi for much assistance, He is also indebted to Prof. $K$. Kageyama for his histological examination and to T. Abe for his technical advice.

\section{REFERENCES}

1. Tomasi, T. B. Jr. and Bienenstock, J.: Secretory immunoglobulins. Adv. Immunol. $9: 1-96,1968$

2. Bienenstock, J.: The significance of secretary immunoglobulins. Can. Med. Assoc. J. $103: 39-43,1970$

3. Tomasi, T. B. Jr. and DeCoteau, E.: Mucosal antibodies in respiratory and gastrointestinal disease. Adv. Intern. Med. 16: 401-425, 1970

4. George, M. and Vaughan, J. H.: In vitro cell migration as a model for delayed hypersensitivity. Proc. Soc. Exp. Biol. 111: 514-521, 1962

5. David, J. R., Al-Askari, S., Lawrence, H. S. and Thomas, L.: Delayed hypersensitivity in vitro. I. The specificity of inhibition of cell migration by antigens. J. Immunol. 93: 264-273, 1964

6. Bloom, B. R. and Bennet, B.: Mechanism of a reaction in vitro associated with delayed-type hypersensitivity. Science $153: 80-82,1966$

7. Myrvik, Q. N., Leake, E. S. and Fariss, B.: Studies on pulmonary alveolar macrophages from the normal rabbit: A technique to procure them in a high state of purity. J. Immunol. 86: 128-132, 1961

8. Galindo, B. and Myrvik, Q. N.: Migratory response of granulomatous alveolar cells from BCG-sensitized rabbits. J. Immunol. 105: 227-237, 1970

9. Henney, C. S. and Waldman, R. H.: Cell-mediated immunity shown by lymphocytes from the respiratory tract. Science 169: 696-697, 1970

10. Yamamoto, K. and Anacker, R. L.: Macrophage migration inhibition studies with cells from mice vaccinated with cell walls of Mycobacterium bovis BCG: Characterization of experimental system. Infect. Immun. 1: 587-594, 1970

11. Waldman, R. H. and Henney, C. S.: Cell-mediated immunity and antibody responses in the respiratory tract after local and systemic immunization. J. Exper. Med. 134: 482-494, 1971

12. Waldman, R. H., Spencer, C. S. and Johnson, J. E. III: Respiratory and systemic cellular and humoral immune responses to influenza virus vaccine administered parenterally or by nose drops. Cell. Immunol. 3: 294-300, 1972

13. Nash, D. R. and Holle, B.: Local and systemic cellular immune responses in guineapigs given antigen parenterally or directly into the lower respiratory tract. Clin. Exp. Immunol. 13: 573-583, 1973

14. Jurgensen, P. F., Olsen, G. N., Johnson, J. E. III, Swenson, E. W., Ayoub, E. M., Henney, C. S. and Waldman, R. H.: Immune response of the human respiratory 
tract. II. Cell-mediated immunity in the lower respiratory tract to tuberculin and mumps and influenza viruses. J. Infect. Dis. 128: 730-735, 1973

15. Gadol, N., Johnson, J. E. III. and Waldman, R. H.: Respiratory tract cell-mediated immunity: Comparison of primary and secondary response. Infect. Immun. 9: 858-862, 1974.

16. Reynolds, H. Y., Thompson, R. E. and Devlin, H. B.: Development of cellular and humoral immunity in the respiratory tract of rabbits to pseudomonas lipopolysaccharide. J. Clin. Invest. 53: 1351-1358, 1974

17. Kino, T.: Dynamic aspects of immunocompetent cells for delayed hypersensitivity: Relationship between macrophage migration inhibition phenomenon and delayed skin reaction. Kekkaku 49: 117-125, 1974 (in Japanese)

18. Cantey, J. R., Hand, W. L., Hughes, C. G., Lund, M. E. and King, N. L.: Cellmediated immunity after bacterial infection of the lower respiratory tract. J. Clin. Invest. 54: 1125-1134, 1974

19. Akiyama, T.: Macrophage migration inhibition test. Modern Media 15: 648-661, 1969 (in Japanese)

20. Yahr, M.: Studies of the macrophage inhibition test. I. Comparison of the skin and cell migration reactions during the course of development of delayed hypersensitivity. J. Immunol. 102: 852-858, 1969

21. Yamamoto, K., Anacker, R. L. and Ribi, E.: Macrophage migration inhibition studies with cells from mice vaccinated with cell walls of mycobacterium bovis BCG: Relationship between inhibitory activity of lung cells and resistance to air borne challenge with mycobacterium tuberculosis H37Rv. Infect. Immun. 1: 595599,1970

22. Bienenstock, J., Johnston, N. and Perey, D. Y. E.: Bronchial lymphoid tissue. I. Morphologic characteristics. Lab. Invest. 28: 686-692, 1973

23. Spencer, J. C., Waldman, R. H, and Johnson, J. E. III : Local and systemic cellmediated immunity after immunization of guinea pigs with live or killed $M$. tuberculosis by various routes. J. Immunol. 112: 1322-1328, 1974

24. Rich, A. R. and Mccordock, H. A.: An enquiry concerning the role of allergy, immunity and other factors of importance in the pathogenesis of human tuberculosis. Bull. Johns Hopkins Hosp. 44: 273-382, 1929

25. Wilson, G. S., Schwabacher, H. and Maier, I.: The effect of the desensitization of tuberculous guinea-pigs. J. Pathol. Bacteriol. 50: 89-109, 1940

26. Crowle, A. J.: Immunizing constituents of the tubercle bacillus. Bact. Rev. 22: $183-203,1958$

27. Uhr, J. W.: Delayed hypersensitivity. Physiol. Rev. 46: 359-419, 1966

28. Dubos, R.: Acquired immunity to tuberculosis. Amer. Rev. Respir. Dis. 90: 505515,1964

29. Mackaness, G. B.: The immunology of antituberculous immunity. Amer. Rev. Respir. Dis. 97: 337-344, 1968

30. Collins, F. M.: Acquired resistance to mycobacterial infections. Adv. Tuberc. Res. 18: $1-30,1972$ 